\title{
THE CRIMINAL ACT OF COMMERCIAL SURROGACY IN AUSTRALIA: A CALL FOR REVIEW
}

\begin{abstract}
Australian surrogacy legislation punishes the pursuit of a commercial surrogacy arrangement as a criminal offence. Such legislation was first introduced in Victoria in 1986 and has since been applied in every Australian jurisdiction except for the Northern Territory. The current application of criminal law is based upon this 1980s policy which has never been subject to public debate. This article argues that the continued application of criminal penalties to commercial surrogacy requires review.
\end{abstract}

\section{INTRODUCTION}

Today in every Australian jurisdiction with the exception of the Northern Territory, specific legislation governs adult reproductive choice with respect to family creation through surrogacy. This legislation renders commercial surrogacy an illegal act, punishable by fines and/or imprisonment.

The crime of commercial surrogacy was first introduced in Victoria in 1986. The introduction of this crime and its subsequent adoption by all other Australian jurisdictions with specific surrogacy legislation has never been questioned by policy makers ${ }^{1}$ and as a consequence has not been opened to public debate. This dearth of discussion surrounding the criminalisation of commercial surrogacy is remarkable in light of the number of public inquiries held across Australian jurisdictions into surrogacy. More than 24 inquiries have been undertaken between 1983 and 2009 with even the most recent wave of legislative reform inquiries into surrogacy, held by the Commonwealth, Tasmania, South Australia, New South Wales and the Victorian governments, ${ }^{2}$ - specifically excluding the issue of commercial surrogacy from each respective terms of reference. For example in 2009 the Standing Committee of Attorneys-General in their Consultation paper titled A proposal for a National Model to harmonise the regulation of Surrogacy

\footnotetext{
${ }^{1}$ See for example the 1991 call by the Australian Health and Social Welfare Ministers to support an ongoing criminal prohibition in all Australian jurisdictions: Anita Stuhmcke, 'Surrogate Motherhood: The Legal Position in Australia' (1994) 2(2) Journal of Law and Medicine 116.

${ }^{2}$ Parliament of South Australia, Inquiry into Gestational Surrogacy, $26^{\text {th }}$ Report (2007); Victorian Law Reform Commission (VLRC), Assisted Reproductive Technology \& Adoption, Report (2007), WA Legislative Council, Select Committee on Legislation, Report on Surrogacy (2008); Legislative Council of Tasmania, Select Committee on Surrogacy, Report (2008); Queensland Parliament, Investigation into Altruistic Surrogacy, Report (2008), NSW Parliament, Inquiry into Altruistic Surrogacy (2009) and Standing Committee of Attorneys-General Australian Health Ministers' Conference Community and Disability Services Ministers' Conference, Joint Working Group, A proposal for a national model to harmonise the regulation of surrogacy, January 2009see SCAG above. For an account of older inquiries see Anita Stuhmcke, 'Looking Backwards, Looking Forwards: Judicial and Legislative Trends in the Regulation of Surrogate Motherhood in the UK and Australia' (2004) 18 Australian Journal of Family Law 13. All but one of those inquiries (the National Bioethics Consultative Committee) expressed grave concerns about surrogacy and recommending prohibition, see, http://www.women.qld.gov.au/resources/criminal-code/documents/chapter-9.pdf. viewed 8 November 2009.
} 
unilaterally states that ' $[\mathrm{T}]$ he proposed model would not permit commercial surrogacy, 3 and as recently as December 2008 the Western Australian Parliament passed the Surrogacy Act 2008 without questioning ${ }^{4}$ the criminal prohibitions on commercial surrogacy a feat replicated by the NSW Assisted Reproductive Technology Act 2010 introduced in January 2010.

This article questions this ongoing application of criminal prohibitions to commercial surrogacy in Australia. It begins by evaluating the legislative prohibition introduced in the 1980 s and argues that the current offence is based upon outdated reproductive policy which fails to reflect factors such as: changed understandings of infertility; a 'new' global marketplace; and an altered social and technological environment. Further, the article observes that the current legislative criterion detailing an illegal commercial surrogacy expenses are both ambiguous and without uniform definition across Australian jurisdictions. Ultimately, the article calls for review of the offence of commercial surrogacy. $^{5}$

\section{THE RATIONALE FOR CRIMINALISING COMMERCIAL SURROGACY}

\section{Why the 'need' for Australian surrogacy legislation in the 1980s?}

Surrogacy has a long history. Australian Torres Strait Islanders have customary adoption practices which may from a Western perspective be labeled as surrogacy; ${ }^{6}$ the practice has been documented through a biblical reference to surrogacy in Genesis; and there are various historical examples of surrogacy occurring such as the private diaries of Winston Churchill's wife Clementine revealed that she offered to give the couple's fourth child to Lady Jean Hamilton, a close family friend, unable to conceive. ${ }^{7}$

Despite these and other examples of surrogacy occurring across cultures and throughout history, government interest in the practice is a relatively recent occurrence, being linked directly to the growth of commercial surrogacy in the United States in the late 1970s and early 1980s. In particular two high profile cases of commercial surrogacy - the 1986 Baby M case ${ }^{8}$ in the United States and the 1985 Baby Cotton $^{9}$ case in the United

\footnotetext{
${ }^{3}$ Ibid 4.

${ }^{4}$ See for example, the Second Reading by the Hon John Moore, 12 November 2008, p153a-155b. This approach is similar in all jurisdictions, for example, when Tasmania introduced legislation criminalising commercial surrogacy in 1993 the prohibition of the practice was not questioned but was justified as being 'in line with the recommendations of a joint meeting of Commonwealth and State ministers responsible for Health and Social Welfare, [the government] does not believe that the legislation should penalize parties to [altruistic] surrogacy'.

${ }^{5}$ This article does not evaluate the arguments for and against the practice - this has been done elsewhere for an argument against commercial surrogacy see for example, Suze G Berkhout, 'Bun in the Oven: Objectification, Surrogacy, and Women's Autonomy' (2008) 34(1) Social Theory and Practice 96. For the arguments in favour see for example, Debora L Spar, 'For love and money: the political economy of commercial surrogacy' (2005) 12(2) Review of International Political Economy 287.

${ }^{6}$ Paul Ban, 'Torres Strait Islander Customary Adoption' (1993) Family Matters 35, 17.

${ }^{7}$ Helen Szoke, 'Surrogacy: All the Features of a Relationship That Could Go Wrong? (2001) 28 Melbourne Journal of Politics.

${ }^{8}$ In the Matter of Baby M, 109N.J. 396, 537 A.2d 1227 (N.J. 1988).
} 
Kingdom - attracted a great deal of international media and public interest. These judicial decisions catapulted surrogacy onto the legislative agenda in most developed countries resulting in a plethora of international government commissions of inquiry into surrogacy in the 1980s. ${ }^{10}$

The central issue raised by Baby $\mathrm{M}$ and Baby Cotton - the payment of money for surrogacy and the issue of whether a surrogacy agreement could be legally enforced as a contract - framed much of the ensuing debate over surrogacy. At that time in Australia it was widely assumed ${ }^{11}$ that commercial surrogacy contracts would be unenforceable at common law due to the public policy heads of sexual immorality; ${ }^{12}$ a contract prejudicial to family life or baby-selling. ${ }^{13}$ Similarly to all other common law jurisdictions however, Australian courts did not have jurisdiction to criminally punish adults for entering into surrogacy arrangements for commercial gain. The use of payment to create a family through a surrogacy arrangement could therefore be prohibited by criminal sanction in Australian jurisdictions only through legislative intervention.

The early legislation introduced in Australia fills this gap. Between 1986 and 1988 prohibition legislation was introduced in Victoria, South Australia and Queensland. ${ }^{14}$ In each of these jurisdictions the purpose of the surrogacy legislation was to impose criminal penalties upon individuals or organizations facilitating commercial surrogacy arrangements. ${ }^{15}$ Today, the absence of regulation of commercial surrogacy at a federal level means that surrogacy legislation remains state and territory specific. The practice of commercial surrogacy is currently a criminal statutory offence in: New South Wales (Assisted Reproductive Technology Act 2007); Victoria (Assisted Reproductive Treatment

\footnotetext{
${ }^{9}$ Re C (A Minor) (Wardship: Surrogacy) [1985] FLR 846

${ }^{10}$ International examples of 1980s inquiries into surrogacy include the American College of Obstetricians and Gynecologists, Ethical Issues in Surrogate Motherhood, 1983; the Canadian Ontario Law Reform Commission, Report on Human Artificial Reproduction and Related Matters, 1985; the French Comite Consultatif National d'Ethique, Opinions on the Ethical Problems of Artificial Reproductive Technologies (1984). See Sue A Meinke, 'Surrogate Motherhood: Ethical and Legal Issues' Scope Note 6, National Reference Center for Bioethics Literature, Surrogate Motherhood Review, 1/88.

${ }^{11}$ While there were then no Australian cases directly on point the Full Court of the Family Court of Australia has now determined legal parentage following a dispute over the custody of a child following the breakdown of a surrogacy arrangement through application of the traditional family law test of 'best interests' of the child rather than contractual principles see: Re Evelyn (1998) 145 FLR 90.

${ }^{12}$ Surrogacy may be achieved by the intending father having sexual intercourse with the surrogate mother.

${ }^{13}$ United Kingdom judicial dicta supports this assumption: see $A v C$ [1985] FLR 445. This assumption has not always been supported in other jurisdictions, most famously in the United States in Baby M (1987) 525 A 2d 1128; Baby M (1988) 537 A 2d 1227.

${ }^{14}$ In Victoria (Infertility (Medical Procedures) Act 1984, Part V, in force on 10 August 1986), South Australia (the Family Relationships Act Amendment Act 1988, in force on 7 April 1988 inserting Part IIB into the Family Relationships Act 1975) and Queensland (Surrogate Parenthood Act 1988 in force on 6 October 1988) (and see the UK the Surrogacy Arrangements Act 1985). Tasmania followed in 1993, the Australian Capital Territory in 1994, Western Australia in 2008 and New South Wales in 2010.

${ }^{15}$ The legislation in Victoria and the UK has since been superseded. At the time the Victorian inquiry resulted in the then Infertility (Medical Procedures) Act 1984 (Vic) imposing a 50 penalty unit or two year sentence of imprisonment upon the publishing of an advertisement with respect to surrogacy or the giving or receiving of payment for a surrogate mother. In the United Kingdom the then Surrogacy Arrangement Act 1985 (UK) established an offence for any person taking part in commercial negotiations leading to a surrogacy arrangement.
} 
Act 2008); Queensland (Surrogacy Act 2008); South Australia (Family Relationships Act 1975); Tasmania (Surrogacy Contracts Act 1993); the Australian Capital Territory (Parentage Act 2004) and Western Australia (Surrogacy Act 2008). The Northern Territory remains the only jurisdiction where there is no specific legislation in force to regulate surrogacy however it is assumed that the combination of National Health and Medical Research Council ethical guidelines and statutes enacted without surrogacy in mind such as the adoption acts would render commercial surrogacy both unenforceable and illegal in that jurisdiction.

\section{Laying the foundations? The disparity between the first government inquiries in Australia and the legislative outcomes}

Given that Australia was a world leader in the use of IVF technologies in the late 1970s and early 1980s it is not surprising that two ${ }^{16}$ of the earliest international government law reform inquiries into the use of IVF occurred in Australia. These inquiries, held in Victoria $^{17}$ and Queensland ${ }^{18}$ were not specific to surrogacy. In Victoria the Terms of Reference for 'The Committee to Consider the Social, Ethical and Legal Issues Arising from In Vitro Fertilisation' centred on IVF $^{19}$ similarly, in Queensland the Report of the Special Committee appointed by the Queensland Government to Enquire into the Laws

\footnotetext{
16 There was also a 1984 Working Party and 1987 Select Committee of South Australia: the 1984 Working Party was a two person report which made little reference to surrogacy however recommended that "no change to the law be made to enable surrogacy to be practiced in South Australia' see Recommendation 23 of the In Vitro Fertilization and Artificial Insemination by Donor in In Vitro Fertilisation and Artificial Insemination by Donor, 28 July 1984, proceedings of the Seminar and Public Lecture held by the South Australian Health Commission, 94. As the 1987 Select Committee was appointed in October 1984 by the Legislative Council of South Australia to report on artificial insemination by donor, in vitro fertilization and embryo transfer procedures and related matters. Surrogacy is not discussed in detail however it is of interest to note that nevertheless the Select Committee declared its opposition to surrogacy.

${ }^{17}$ Victorian Committee to Consider the Social, Ethical and Legal Issues Arising From In Vitro Fertilization, Report on Donor Gametes in IVF (1983), Report on the Disposition of Embryos Produced by In Vitro Fertilisation, 1984, para 4.17, Victoria, Australia. Victorian Committee to Consider the Social, Ethical and Legal Issues Arising From In Vitro Fertilization. Known as the Waller Report this Committee was established by the Victorian Government on 24 May 1982. The reports of the Committee were published in two parts - part one on donor gametes published in 1983 and the second report which refers to surrogacy is published in August 1984.

${ }^{18}$ Demack J, Report of the Special Committee Appointed by the Queensland Government to Enquire into the Laws Relating to Artificial Insemination, In Vitro Fertilisation and Other Related Matters, (Qld Parliament, Brisbane, Volumes I and II 1984) (Demack report). Known as the Demack Report the Committee was established by the Queensland Cabinet on 8 February 1983 and the report was published on the $1^{\text {st }}$ March 1984.

${ }^{19}$ The committee was established to 'consider whether the process of in vitro fertilization (IVF) should be conducted in Victoria and if so, the procedures and guidelines that should be implemented in respect of such processes in legislative form or otherwise.' Committee to Consider the Social, Ethical and Legal Issues Arising From In Vitro Fertilization' Interim Report September 1982, at 1.1. The Committee regarded 'surrogate motherhood in IVF' as a 'separate matter' see n 17, at 4. The Committee acknowledged that the practice can take place outside of IVF. The Committee decided to review all aspects of the subject while noting that non-IVF aspects of surrogacy were specifically outside the Committee Terms of Reference, n 4 at $49-50$.
} 


\section{Relating to Artificial Insemination, In Vitro Fertilisation and Other Related Matters} focused upon surrogacy only in so far as it related to AI and IVF. ${ }^{20}$

While neither inquiry recommended the application of criminal law to surrogacy, explicit disapproval of the practice was expressed. The Waller Report 'recommends that surrogacy arrangements shall in no circumstances be made at present as part of an IVF programme in Victoria" ${ }^{\text {,1 }}$ observing that '[T]he Committee has come to the conclusion that surrogate mother arrangements where fees are paid are, in reality agreements for the purchase of a child, and should not be countenanced. ${ }^{22}$ Similarly to the Victorian Waller Report, the Demack Report states that 'it would not be desirable...to make surrogacy arrangements criminal offences...'. ${ }^{23}$ However the Committee then goes on to note that '.. it should be made illegal to advertise to recruit women to undergo surrogate pregnancy, or to provide facilities for persons who wish to make use of the services of such women. 24

Despite this absence of recommendation that criminal law be applied to the surrogate mother or intending parents in commercial surrogacy arrangements the outcome in Victoria and Queensland was to attach criminal penalties to their actions. Following the Waller Report in Victoria the Victorian Parliament passed the Infertility (Medical Procedures) Act 1984. Section 30 of the Act dealt with surrogate motherhood and under that provision, which came into operation on 10 August 1986, any payment made pursuant to a surrogate motherhood agreement will result in a fine or two years imprisonment. Advertising was also prohibited under the Act which specifically provided that all surrogacy "contracts" are void. Similarly, in Queensland the Surrogate Parenthood Act 1988 (recently repealed ${ }^{25}$ ) criminalised both commercial surrogacy and altruistic surrogacy attaching penalties to the parties to the arrangement.

In Victoria no public justification is provided for the application of criminal law to the participants in a commercial surrogacy arrangement. The first version of the Infertility (Medical Procedures) Bill was introduced to Victorian Parliament in March 1984 - by October 1984 the fourth revision of the Bill (Infertility (Medical Procedures) Bill (No. 2) contained new amendments criminalizing commercial surrogacy. The Attorney-General the Hon J H Kennan noted that the amendments:

...will effectively pre-exempt the recommendations of the Waller Committee. For myself, I have indicated, when introducing the Bill, that at least in regard to surrogacy, we are prepared to do that. There does not seem to be much

\footnotetext{
${ }^{20}$ Demack Report, n 18, Volumes I and II.

${ }^{21}$ Waller Report n 17, at 54 para 4.17.

${ }^{22}$ Waller Report n 17, at 50 para 4.6. While the Committee did not recommend the application of criminal law to surrogacy it did note that ' $[\mathrm{S}]$ ome members of the Committee consider that the criminal law should be amended to make it clearly an offence to enter into, or contribute in any way to, a commercial surrogacy agreement.' at 51, para 4.7 .

${ }^{23}$ Demack Report, n 18 at 117.

${ }^{24}$ Ibid 118.

${ }^{25}$ This has now been repealed and the Surrogacy Act 2010 (Q1d) introduced which decriminalises altruistic surrogacy.
} 
community debate about surrogacy. I believe the provisions in the Bill meet with general acceptance and appear to have met with the general acceptance of honourable members. ${ }^{26}$

This absence of public consultation on surrogacy is confirmed by the Honourable JR Kirner who notes in the same debate that '[T]he Bill also provides answers to a number of questions that are...now community questions and not just questions for Parliament...the Bill does not pre-empt community discussion on the final Waller report, except in the case of surrogate motherhood. ${ }^{27}$

There is difference between the parliamentary debate in Victoria and Queensland. In Victoria surrogacy is treated moderately - almost dismissively - whereas in Queensland the debate is one of condemnation and moral outrage, best summarized by comments such as those form the Honourable PR McKechnis who states in the second reading speech for the Surrogate Parenthood Act 1988 that '[I]t is the strong belief of members of the Queensland Government that to use or to pay another human being to reproduce is the ultimate in dehumanisation. We are of the opinion that a baby must not be treated as a commodity to be purchased. It must not be the subject of traffic in any form. ${ }^{28} \mathrm{Mr}$ Stephan (Member for Gympie) similarly observes that:

Honourable members should ask themselves whether they want a society where there is a "rent a womb"; where women are used as incubators; where the surrogate mother seeks to deny her parental responsibility; where a child would be created deliberately to be abandoned by one of its parents; and where women of low socio-economic status may seek to become "breeders" for economic reasons. Alternatively, is the future of the world one where carrying a child and the physical risks and emotional upheaval associated with pregnancy and childbirth seem to be ignored or denied; where people are used in this matter as a means to ends; and where the intimate relationship between mother and child is dehumanized to a working relationship between a unit of manufacture and its product? ${ }^{29}$

The stark difference in the tone of parliamentary debate in Victoria and the moralistic condemnation in Queensland may be explicable through jurisdictional differences and/or external events such as the timing of the UK Baby Cotton case in 1985 and the US Baby M case of 1986 as these high profile cases occur after the Victorian legislation is introduced and before the parliamentary debates occur in Queensland. Regardless however of difference in tone, the result of the debate by legislatures in both jurisdictions is to render commercial surrogacy a criminal act and thus largely ignore the recommendations of their respective parliamentary inquiries.

\footnotetext{
${ }^{26}$ Hon JH Kennan Legislative Council, 11 October 1984, 770. On this point the Hon JV C Guest states with respect to Kennan's comment that '..it is very odd to hear from a noted civil libertarian that because people in the community regard something as offensive then it should be stopped.' Legislative Council, 11 October 1984, 767.

${ }^{27}$ Hon JE Kirner, Legislative Council, 11 October 1984, 762.

${ }^{28}$ Second Reading Speech, Surrogate Parenthood Bill, 23 March 1988, 5546.

${ }^{29}$ Second Reading Speech, Surrogate Parenthood Bill, 7 September 1988, 66.
} 
Of course there is no requirement for parliaments to adhere to the findings of government inquiries. Indeed at the time there are common issues across both jurisdictions - peculiar to commercial surrogacy - which render understandable this divergence between parliament and its reports. Firstly, on an international level there was significant movement between the recommendations of the Waller and Demack Reports and the passing of legislation in Victoria and Queensland. In particular the Warnock Committee $^{30}$ in the UK, established in July 1982, reported its findings ${ }^{31}$ on the application of criminal penalties to surrogacy. These recommendations were influential in Australia. ${ }^{32}$ Secondly, the jurisdictions of Victoria and Queensland followed what can now (with benefit of hindsight) be viewed as an established legislative pattern across jurisdictions dealing with biomedical innovation. This pattern is to respond to biomedical developments (such as embryo freezing; ${ }^{33}$ cloning, xenotransplantation and surrogacy) by initially applying the heavy handed legal regulatory model of criminal law and then consequently adopt more nuanced and flexible regulatory frameworks.

\section{Were the Victorian and Queensland 1980 criminal prohibitions justified?}

The issue as to whether the current application of criminal law to commercial surrogacy is justified is however an essentially different question as to whether the imposition of such a penalty in the 1980s was understandable. Criminal penalties, the most serious sanctions in the Australian legal system, are arguably only justified in liberal theory when the punishment imposed is necessary to prevent harm. ${ }^{34}$ As Mill states, a free society should protect '... [the] liberty of tastes and pursuits... without impediment from our fellow creatures, so long as what we do does not harm them, even though they should think our conduct foolish, perverse or wrong. ${ }^{, 35}$ It is therefore desirable that the criminal act of commercial surrogacy originated to prevent harm or to ensure the safety of the population. In other words criminal restrictions on procreative liberty may be justified if surrogacy substantially burdens others. ${ }^{36}$ Optimally, in a liberal democratic society such as Australia, the prevention of an exercise in personal choice should be supported by a rational explanation for government action. The continuing prohibition upon commercial surrogacy which renders this reproductive opportunity ${ }^{37}$ a criminal act must therefore be grounded in reason or, at least, not be unreasonable.

\footnotetext{
${ }^{30}$ United Kingdom, Department of Health and Social Security, Report of the Committee of Inquiry into Human Fertilisation and Embryology (1984) (Warnock Committee Report).

${ }^{31}$ Ibid, para 8.18 at 46: 'We recognise that there is a serious risk of commercial exploitation of surrogacy and that this would be difficult to prevent without the assistance of the criminal law'.

${ }^{32}$ See the Commonwealth Government, Family Law Council, Creating Children: A uniform approach to the law and practice of reproductive technology in Australia, AGPS, 1985 at 65.

33. In Victoria this point was brought home when a couple, Mr and Mrs Rio died in a 1983 plane crash leaving 'orphaned embryos' in storage see 'Panel in Australia Urges that Orphaned Frozen Embryos be Destroyed', New York Times, September 4, 1984. On the point as to the knee jerk reaction of prohibition see also comments of the Commonwealth Government, Family Law Council, n 32 at 65.

${ }^{34}$ John S Mill, On Liberty and Other Essays (1991).

35 Ibid, 12.

${ }^{36}$ John A Robertson, 'Embryos, Families, And Procreative Liberty: the Legal Structure of the New Reproduction' (1985-1986) 59 Southern California Law Review 939 at 954.

${ }^{37}$ Proponents of surrogacy would see commercial surrogacy as a right to procreate: Ibid at 102-3.
} 
Whether the criminalization of surrogacy is based upon reason has been questioned by even the original architects of criminal policy. For example Dame Warnock, the Chair of the Warnock Report has altered her 1980s position on surrogacy stating in 2002 that 'I now believe that it would be better if the process were officially regulated, and more openly discussed between doctors, prospective parents, surrogates, and, later, with the resulting children. ${ }^{38}$ She goes on to note that

.the hasty legislation was rushed through in the UK at the end of a Parliamentary session in 1989..on a wave of revulsion against anything so vulgar and exploitative as the American commercial companies who were hovering on the shores of Britain. The general sentiment was 'not in our backyard'. If people wanted to enter into surrogacy contracts, let them go across the Atlantic to do it. I do not remember any very serious discussion of whether or not surrogacy was so intrinsically so immoral, or its consequences so socially disastrous, that legislation against it must be enacted...I increasingly believe that one social ill we need to be aware of is that of excessive governmental regulation. If surrogacy were allowed in the UK, on the American model, though some people might be offended, I doubt if we would be harmed...I suspect that the legislation hastened through at the time of the Committee of Inquiry into Human Fertilisation and Embryology was mistaken. ${ }^{39}$

The current Australian legislative criminal prohibition of commercial surrogacy similarly originates from this 1980 s climate of fear.

\section{JUSTIFYING A CALL FOR LEGISLATIVE REVIEW}

In 1984 in the Victorian Parliament Mr F P Sheehan, the member for Ballarat South, states in relation to the passage of the Victorian Bill which criminalized commercial surrogacy that, '[O]n a personal level, dealing with the Bill is like walking into a dark room and not knowing where all the furniture is placed. ${ }^{40}$ To date there has still been no effort by any Australian legislature to ascertain where the furniture is placed with respect to commercial surrogacy or to acknowledge that even the room itself may have substantially altered in the almost three decades since the policy was implemented.

It is now necessary that such efforts be made - review of the application of criminal penalties is required for the following reasons:

\section{A changed global, social and technological environment}

In the thirty years since legislation was introduced the surrogacy landscape has fundamentally altered. Today a myriad of factors have lead to a increasing ${ }^{41}$ and public

\footnotetext{
${ }^{38}$ Mary Warnock, Making Babies: is there a right to have children? Oxford University Press, $2002,92$.

${ }^{39}$ Ibid, at 92-93.

${ }^{40}$ Mr FP Sheehan, Legislative Assembly, 2 November 1984 at 1825.

${ }^{41}$ Evidence as to the extent of the use of surrogacy is not available, as the 2008 Tasmanian inquiry wrote that while surrogacy is not a commonly performed medical procedure (Parliament of Tasmania, Legislative
} 
use of surrogacy to create families including: the declining number of children available for adoption; ${ }^{42}$ a global marketplace; growing infertility; ${ }^{43}$ increasing leaps forward in scientific technology for the purposes of human reproduction; the lack of options for some couples, ${ }^{44}$ and a more accepting public attitude towards the application of such technology. ${ }^{45}$ The result is that perceptions as to treatment for infertility is very different today to what it was in the 1980s when criminal prohibition of commercial surrogacy was introduced.

For example, there is now a social phenomenon of individuals interacting across jurisdictions in what may be described as a global reproductive network for the chance to parent a child. ${ }^{46}$ In Australia legal restrictions on access to ART for surrogacy over the past three decades has resulted in 'medicine by postcode" ${ }^{47}$ where ineligible parents travel interstate for treatment. Indeed fertility services in restricted states have actively facilitated such treatment. ${ }^{48}$ The application of criminal law to commercial surrogacy has also resulted in Australians engaging in international surrogacy arrangements ${ }^{49}$ with commercial surrogacy and egg donation being well established in the US and rapidly evolving in countries such as India. ${ }^{50}$

\section{Empirical evidence as to community views}

Council Select Committee Report on Surrogacy, 2008 at 10) '...the Committee has found that surrogacy is a fact of life in Tasmania' (2008).

${ }^{42}$ In NSW there were 84 inter-country adoptions and 9 local adoptions in 2005: DOCS e-newsletter January 2007. The total number of adoptions in Australia is 5\% of what it was 30 years ago: House of Representatives, Standing Committee on Family and Human Services, Overseas Adoption in Australian: Report on the Inquiry into Adoption of Children from Overseas (2005), 1-2.

43 Australian Institute of Family Studies, 'It's Not for Lack of Wanting Kids': A Report on the Fertility Decision Making Project (2004). ACCESS estimates that one in six Australian couples are infertile - these figures of course relate to heterosexual couples and do not take into account single people or homosexual couples who may wish to pursue surrogacy.

${ }^{44}$ Not all of these people are able to access ART procedures - medical reasons such as a woman not having a uterus or a medical condition which makes pregnancy life threatening may mean that surrogacy is the only available option for them.

${ }^{45}$ See AE Poote \& OBA van den Akker 'British women's attitude to surrogacy' (2008) Human Reproduction. There are however studies which support the view that surrogacy is the least acceptable of all assisted reproductive technologies see: Janice C Ciccarelli \& Linda J Beckman, 'Navigating Rough Waters: An Overview of Psychological Aspects of Surrogacy’ (2005) 61(1) Journal of Social Issues 21, 29. Gabor T Kovacs, Gary Morgan, E Carl Wood, Catherine Forbes and Donna Howlett 'Community attitudes to assisted reproductive technology: a 20-year trend' (2003) 179(10) Medical Journal of Australia at 536-538.

${ }^{46}$ Goodwin M, ‘Altruism's Limits: Law, Capacity and Organ Commodification' (2004) 56 Rutgers Law Review, 305 at 320.

${ }^{47}$ Dr Christine Kirby, Oral evidence to South Australia, Inquiry into Gestational Surrogacy, Social Development Committee, Report 26 (2007) at 27.

${ }^{48}$ Kerry Petersen et al, 'Assisted Reproductive Technologies: Professional and Legal Restrictions in Australian Clinics' (2005) 12 Journal of Law and Medicine 373 at 383.

49 'Gay Aussies flock to US for 'one stop baby shop' The Australian, July 1, 2008. It is interesting to note the argument that there is an international obligation not to push our unwanted practices into other countries: Richard F Storrow, 'Quests for Conception: Fertility Tourists, Globalization and Feminist Legal Theory’ (2005-2006) 57 Hastings Law Journal 295.

${ }^{50}$ Amelia Gentleman, 'India Nurtures Business of Surrogate Motherhood' New York Times 10 March 2008; http://indiahealthtour.com, viewed 9 September 2009. 
Policymakers do acknowledge that public opinion in the area of reproductive regulation is important. For example in the 1980s the Victorian Attorney-General believed the Waller Report to be of such significance that he announced the report was to be the subject of community evaluation and consultation between the time it was available in September and in December. This caused the opposition Shadow Minister for Health to state '..I am somewhat troubled that, as Parliament would be rising early this year, the House would be required to deal with the Bill before the outcome of the community consultation was fully available for members of Parliament of all parties. ${ }^{51}$ The passage of this Bill through parliament meant that 'honorable members are being required to debate the measures before we know the outcome of community consultation. ${ }^{52}$

The importance attached to public opinion is also acknowledged in the regulation of commercial surrogacy. Where mentioned it appears that the belief of the 1980s policymakers was that criminalization of commercial surrogacy reflected community opinion. For example, the South Australian inquiry began from the premise that 'the correct approach is to devise legislation which reflects the collective conscience of society ${ }^{53}$ and the UK Warnock Report concluding that '[T]here are strongly held objections to the concept of surrogacy, and it seems from the evidence submitted to us that the weight of public opinion is against the practice'. 54

This assumption that the Australian community views commercial surrogacy as requiring criminalisation is however made in the absence of evidence. The data that was available in the 1980s opens to question the veracity of this perception as to the public being antipayment for the provision of surrogacy. Specifically, in November 1986 the NSW Law Reform Commission reported on the results of a national sample survey on aspects of surrogate motherhood arrangements. The survey found that ' $[\mathrm{T}]$ here is clearly support among Australians for providing some form of payment to the surrogate mother. $40 \%$ of Australians would pay the surrogate mother her medical expenses plus an agreed fee. A further $34 \%$ considered that the surrogate mother should receive payment for medical expenses only. Only $17 \%$ though that there should be no payment at all. ${ }^{55}$ Now dated, this survey indicates that there is community support for the view that some degree of commercial surrogacy is acceptable to the community.

\section{Empirical evidence as to harm of the practice of surrogacy}

As previously noted in liberal theory the imposition of criminal law as punishment is legitimate when it is necessary to prevent harm.

\footnotetext{
${ }^{51}$ Mr Lieberman, Legislative Assembly, 2 November 1984, 1808.

${ }^{52}$ Mr Lieberman, Legislative Assembly, 2 November 1984, 1808.

${ }^{53}$ In Vitro Fertilisation and Artificial Insemination by Donor, Speech by the then Minister of Health, Dr John Cornwall, 28 July 1984, proceedings of the Seminar and Public Lecture held by the South Australian Health Commission, 2.

${ }^{54}$ Warnock Report, n 29, at 44 para [8.10].

${ }^{55}$ The survey covered 2476 people aged 14 and over in all States of Australia by the Roy Morgan Research Centre: NSW Law Reform Commission Surrogate Motherhood: Australian Public Opinion, Research Report, RR2 1987, xix.
} 
Empirical evidence as to the harm of the practice upon the surrogate mother, the intending parents or the children born from surrogacy is ambiguous. ${ }^{56} \mathrm{~A}$ recent study by Tamsin which examines existing empirical studies of surrogates ${ }^{57}$ finds that the reality is that surrogates do not regret their decision, experience no psychological problems and express feelings of pride and accomplishment. ${ }^{58}$ In the United States estimates are that 25000 women have given birth through surrogacy and that $99 \%$ of those have willingly relinquished the child and found the experience to be positive and that less than $1 \%$ of cases end up with disputed custody in the court system. ${ }^{59}$ Further, since the passing of criminal laws in the 1980s empirical evidence as to the impact of surrogacy is building for example current research confirms that children born through surrogacy are no worse or better off than children born through other means. ${ }^{60}$

\section{Enforcement and effect of criminal law}

The aim of the 1980s reports was not to centre the needs of infertile individuals or surrogate mothers. ${ }^{61}$ Reproductive choice is however a profoundly personal area. Empirical regulatory research into whether compliance with rules is shaped by harsh penalties shows that the use of threat and legal authority (particularly when viewed as unreasonable) can produce the opposite behavior from that sought - with actions being 'more likely to result in non-compliance, creative compliance, criminal behavior or overt opposition. ${ }^{, 62}$ This would seem to apply to the application of criminal law to commercial surrogacy. History demonstrates that any restrictions placed upon the practice of surrogacy will be circumvented by individuals for whom surrogacy may afford their only

\footnotetext{
${ }^{56}$ It is interesting to note that few studies are concerned with intended parents, for example 27 studies have focused upon the surrogate mother and 4 upon the intending parents: see Janice C Ciccarelli \& Linda J Beckman, 'Navigating Rough Waters: An Overview of Psychological Aspects of Surrogacy' (2005) 61(1) Journal of Social Issues 21, 24.

${ }^{57}$ Elly Tamsin, 'The social construction of surrogacy research: An anthropological critique of the psychosocial scholarship on surrogate motherhood' (2008) 67 Social Science and Medicine 1104.

58 Elizabeth FS Roberts (ed), 'Native' Narratives of Connectedness, Cyborg Babies: from Techno-Sex to Techno-Tots (1998). The most popular motivations for surrogates across all studies has been an enjoyment of being pregnant, a feeling of sympathy for childless couples, a desire to earn money as stay-at-home mums, and a desire to do something 'special': see Tamsin, ibid at 1110.

${ }^{59}$ Tamsin, ibid, 1104.

${ }^{60}$ Today evidence mounts that surrogacy does not impact negatively upon participants to or children born of such arrangements. See data from a set of related longitudinal studies in the UK led by Susan Golombok, including: Vasanti Jadva et al, 'Surrogacy: The Experiences of Surrogate Mothers' (2003) 18 Human Reproduction 2196; Fiona MacCallum et al, 'Surrogacy: The Experience of Commissioning Couples' (2003) 18 Human Reproduction 1134; Susan Golombok et al, 'Surrogacy families: Parental functioning, Parent-child Relationships and Children's Psychological Development at Age 2' (2006) 47(2) Journal of Child Psychology and Psychiatry 213. See also numerous studies conducted by van den Akker in the UK, eg: 'Genetic and Gestational Surrogate Mothers' Experience of Surrogacy' (2003) 21(2) J Reprod Infant Psychol 145, 'A Longitudinal Pre Pregnancy to Post Delivery Comparison of Genetic and Gestational Surrogacy’ (2005) 26 J Pyschosom Obstet Gynecol 27.

${ }^{61}$ Demack Report, n 17 at 5 . The Demack Report received 65 written submissions and had interviews with 'two couples involved in IVF' and 'a woman who had a successful pregnancy following IVF treatment'Kieron O’Hara, 'Conflict Overrules Consensus' < http://eprints.ecs.soton.ac.uk/12491/1/Warnock-thes-ohara.pdf $>$ viewed 22 April 2009.

${ }^{62}$ Kristina Murphy, Tom R Tyler \& Amy Curtis, 'Nurturing regulatory compliance: Is procedural justice effective when people question the legitimacy of the law?' (2009) 3 Regulation \& Governance at 2.
} 
chance to create a family. This reality is borne out by media reports and judicial decisions. Despite the existence of often high profile media cases where Australians have either jurisdiction shopped or used international commercial surrogacy agencies, there is also almost no ${ }^{63}$ enforcement of the criminal prohibitions in Australia. For example, in Victoria the offences have not been used despite parents quite openly declaring to courts when seeking parentage orders that they have utilized commercial surrogates in the United States to have the child which is before the court. ${ }^{64}$

Finally, an important outcome of the continued application of criminal penalties is to restrict debate and remove any possibility of constructive dialogue concerning the risks and benefits of the practice. In the absence of debate the assumed community consensus with respect to criminalising commercial surrogacy becomes a self-fulfilling prophecy. Adults who have successfully pursued commercial surrogacy internationally or within Australia will not risk stigmatization to their children through attracting media attention or possible prosecution of themselves. Consensus with respect to the application of criminal law is then assumed as there is no lobby group campaigning for the decriminalisation of commercial surrogacy - and there will be no lobby group until the practice is decriminalised. The assertion that criminal law is appropriate for commercial surrogacy is then legitimized as it removes the possibility of proponents of successful commercial surrogacy arrangements having an opportunity to either explain their position or to communicate the risks and the benefits to others.

\section{The ambiguity of the offence and the inconsistency of penalties}

Surrogacy arrangements may be commercialized to varying degrees. At one end of the spectrum are informal arrangements in which no benefit is provided to the surrogate mother. At the other end are fully commercial contracts brokered by a professional surrogacy agency. In between there is a myriad of intermediate possibilities, such as relatively informal arrangements that nonetheless involve monetary or other benefits being provided to the surrogate mother. While there is escalating acceptance by Australian legislatures of reimbursement of expenses for altruistic surrogacy, the point at which an arrangement crosses from being altruistic to commercial is neither uniform nor clearly articulated in legislation:

- In the ACT section 40 of the Parentage Act 2004 defines a 'commercial substitute parent agreement' as 'a substitute parent agreement under which a person agrees to make or give to someone else a payment or reward, other

\footnotetext{
${ }^{63}$ In Queensland, which until recently had the most extreme criminal provisions, there are few examples where parties to a surrogacy agreement have been penalised seriously. The Queensland Children's Services Act 1965 has been invoked to remove a child from the home of intended parents in 1991 thwarting the efforts of a group of friends to complete an informal surrogacy arrangement. The surrogate mother and intended mother were both charged under the Surrogate Parenthood Act 1988 (interestingly the intended father was not) but the Magistrate discharged the women without recording a conviction.' See http://www.women.qld.gov.au/resources/criminal-code/documents/chapter-9.pdf viewed 10 October 2009.

${ }^{64}$ Loane Skene, 'Women's reproductive rights: the legal limits' Lesbia Harford Oration Melbourne, 23 July 2003 http://www.vwl.asn.au/portals/0/downloads/WomensReproductiveRights.pdf viewed 3 June 2009.
} 
than for expenses connected with (a) a pregnancy (including any attempt to become pregnant) that is the subject of the agreement; or (b) the birth or care of a child born as a result of that pregnancy'.

- In NSW section 42 of the Assisted Reproductive Technology Act 2007 defines 'commercial surrogacy agreement' to mean 'a surrogacy agreement involving a fee or reward to the woman who gives birth, or intends to give birth, to the child that is the subject of the agreement.'

- In Queensland section 10 of the Surrogacy Act 2010 states that a 'surrogacy arrangement is a commercial surrogacy arrangement if a person receives a payment, reward or other material benefit or advantage (other than the reimbursement of the birth mother's surrogacy costs) for the person or another person...' Section 11 defines the meaning of the costs which may be paid as the birth mother's surrogacy costs to include her 'reasonable costs associated with (a) becoming or trying to become pregnant; (b) a pregnancy or a birth; (c) the birth mother and the birth mother's spouse (if any) being a party to a surrogacy arrangement or proceedings in relation to a parentage order.' This Act is the most comprehensive in defining reasonable medical and legal costs.

- In South Australia section 10F Family Relationships Act 1975 (also attaches to third parties) prohibits 'valuable consideration', which, in relation to a contract, means consideration consisting of money or any other kind of property that has a monetary value.

- In Tasmania the Surrogacy Contracts Act 1993 section 4 states that '(4) A person must not make or receive, or agree to make or receive, a payment or reward in relation to a surrogacy contract.'

- In Victoria section 44 of the Assisted Reproductive Treatment Act 2008 states under the heading 'Surrogacy costs' that '(1) A surrogate mother must not receive any material benefit or advantage as a result of a surrogacy arrangement.'

- In Western Australia section 6 of the Surrogacy Act 2008 (WA) states that a surrogacy arrangement is effectively a commercial arrangement when it is '...for reward if the arrangement provides for any person to receive any payment or valuable consideration other than for reasonable expenses associated with (a) the pregnancy or the birth; or (b) any assessment or expert advice in connection with the arrangement.' Payments are alloable under section 7 which provides that an obligation under the surrogacy arrangement to reimburse reasonable expenses may be enforced. 'Reasonable expenses' in relation to the pregnancy include: costs associated with achieving, or attempting to achieve, the pregnancy as long as they a reasonable medical expense that is not recoverable under any health 
insurance or other scheme including related insurance and psychological counselling; the value of earnings foregone because of leave taken may also be reasonable as long as it is for a period of not more than 2 months during which the birth occurs or was expected to occur; or at any other time for medical reasons arising during the pregnancy.

There is thus wide jurisdictional disparity in the offences. For example, payments in Queensland that may be viewed as payments for 'reasonable medical expenses' may in South Australia attract a fine or imprisonment as the giving of valuable consideration.

Ambiguity also exists as to what amount ${ }^{65}$ or form of payment may constitute a 'material benefit or advantage' in jurisdictions such as Victoria and Queensland or 'valuable consideration' in Western Australia and South Australia or 'fee or reward' in New South Wales. While it is possible to argue that a commercial payment in those jurisdictions arises when it takes place outside reimbursement of receipted expenses ambiguity arises as it is possible to view such payments as 'compensating' the surrogate mother for a costly act. In this sense such payments beyond receipted medical and legal expenses are not 'valuable consideration' nor are they 'a material benefit or advantage' nor are they a 'fee or reward'. Rather they compensate a woman for ' ... a twenty-four hour per day job that lasts for nine months. The job involves danger to the woman's life and health. There is no vacation time from this job, and there are few tangible perks. Clearly surrogates deserve compensation for their services. ${ }^{, 66}$

Australia is not alone in the legal conundrum of defining illegal expenses. International legislation reflects the difficulty of creating a dichotomy between the two forms of surrogacy. In the UK while section 2(1) of the Surrogacy Arrangements Act 1985 prohibits the negotiation of a surrogacy agreement 'on a commercial basis' and makes the facilitation of a surrogacy arrangement through advertising a criminal offence there is ambiguity as to what commercial surrogacy is. There is, as the Brazier report notes a recognition that 'surrogacy is, in effect, increasingly being practiced upon a commercial

\footnotetext{
${ }^{65}$ High profile surrogacy cases such as the 2006 birth of a child to a Federal Senator - Stephen Conroy and his wife who was infertile due to ovarian cancer indicates that expenses of between $\$ 40000$ to $\$ 50000$ will be classified as altruistic payments. It is not clear whether a proportion of that amount was paid to the surrogate mother: see the Tasmanian Legislative Select Committee on Surrogacy, 1 July 2008, Witness Senator Stephen Conroy, http://www.parliament.tas.gov.au/ctee/Transcripts/1\%20July\%2008\%20\%20Conroy.pdf viewed 15 October 2008. The financial burden for IVF surrogacy is compounded because the intending parents and birth mother are excluded from Medicare funding.

${ }^{66}$ Jennifer L Watson, 'Growing A Baby for Sale or Merely Renting a Womb: Should Surrogate Mothers Be Compensated for their Services?' (2006-2007) 6 Whittier Journal of Child and Family Advocacy 529, 552. One way to compensate the surrogate may be to recognize that bearing a child involves pain and suffering and to thus add to the list of 'reimbursements' payments for 'pain and suffering'. It must be noted that in Israel where a similar provision was enacted this had the unintentional consequence of legalizing commercial surrogacy: see the Surrogate Motherhood Agreements Law as discussed in Ruby L Lee, 'New Trends in Global Outsourcing of Commercial Surrogacy: A Call for Regulation' (2009) 20 Hastings Women's Law Journal 279, 296.
} 
basis ${ }^{67}$ with typical payments being around 10000 pounds. More recently in the UK an English couple who had a child with a paid surrogate in the Ukraine were prevented from returning to the UK with the child for several months until discretionary leave was granted by the Minister. ${ }^{68}$ Notably, the case concluded that payment to the surrogate, which amounted to the cost of an apartment, satisfied the 'reasonable expense' criterion in the legislation. This allowed parentage rights to be granted under UK law. The court noted that a finding that the expenses were unreasonable would have had the effect of rendering the child stateless and parentless.

Finally, the inconsistency in the options available for sentencing individuals or corporations ${ }^{69}$ involved in commercial surrogacy throughout Australia requires review. The table below demonstrates the jurisdictional differences between offences for commercial surrogacy. ${ }^{70}$

\begin{tabular}{|l|c|c|c|c|c|c|c|}
\hline & NSW & ACT & WA & QLD & VIC & TAS & SA \\
\hline Corporate Fine & $\$ 275000$ & & & & & & \\
\hline Individual Fine & $\$ 110000$ & $\$ 11,000$ & $\$ 24000$ & $\$ 10,000$ & $\$ 28037$ & $\$ 6000$ & $\$ 4,000$ \\
\hline Imprisonment & 2 years & 1 year & 2 years & 3 years & 2 years & 1 year & 1 year \\
\hline \hline
\end{tabular}

While there is no requirement for uniformity between Australian jurisdictions - it has continually been viewed as a desirable goal. This is evidenced by the 1991 resolution Council of Social Welfare Ministers and the more recent 2009 SCAG recommendations.

\section{CONCLUSION}

Surrogacy has historically been a confronting practice. It is therefore not surprising that the state has reacted with condemnation to a form of family creation which brings a third party into reproduction, has the potential to be a commercial industry and fractures concepts of parenthood. As a biomedical development, commercial surrogacy emerged into an unregulated legal environment. ${ }^{71}$ Essentially the current application of criminal

\footnotetext{
${ }^{67}$ Brazier M, Campbell A, Golombok S, eds: Surrogacy: Review for health ministers of current arrangements for payments and regulation - Report of the review team; Cm. 4068. (HMSO/United Kingdom Department of Health), 1998 , para 1.13.

${ }^{68}$ X \& Y (Foreign Surrogacy) [2008] EWCH 3030.

${ }^{69}$ Penalty units are adjusted as at 2009-2010 financial year.

${ }^{70}$ New South Wales (Assisted Reproductive Technology Act 2007) s 43

Victoria (Assisted Reproductive Treatment Act 2008) s 44

Queensland (Surrogacy Act 2010) s 56

South Australia (Family Relationships Act 1975) s 10H

Tasmania (Surrogacy Contracts Act 1993) s 4

Australian Capital Territory (Parentage Act 2004) s 41

Western Australia (Surrogacy Act 2008) s 8

In New South Wales, Victoria and the Australian Capital Territory the offence can be both fine and imprisonment for an individual.

${ }^{71}$ For example, the birth of Louise Brown on 25 July 1978 in England - the first child to be born using IVF - gave rise to an international anxiety about the new developments as the realisation dawned that assisted reproductive technologies had been left largely unregulated: see Elizabeth Ann Pitrolo, 'Birds, the Bees,
} 
law to surrogacy in Australia originates from a form of 'legal moralism' whereby 1980s lawmakers enacted law prohibiting commercial surrogacy to prevent a future harm from arising and as a means of expressing certain values, rather than for the purpose of governing society. ${ }^{72}$

While the practice of surrogacy necessarily means that policymakers must deal with complex and conflicting moral, ethical, political and scientific issues when choosing an appropriate regulatory vehicle it is nevertheless critical that the law be perceived to be in step with social, economic and technological change. Since the application of criminal law to commercial surrogacy thirty years ago, reproductive technologies have evolved from being experimental to being routine in the treatment of infertility. Commerce is now intimately integrated with the provision of fertility treatment in Australia and such treatment is seen as a social good in alleviating the 'harm' of infertility. ${ }^{73}$ As Eggen notes 'governmental attitudes toward the advanced reproductive technologies is closely tied to societal attitudes towards infertility in general. Until recently, infertility was viewed as a social condition that affected a small, silent segment of the population, rather than as a medical problem of almost epidemic proportions. ${ }^{74}$ Surrogacy is becoming increasingly prevalent as a means of alleviating the emotional and psychological devastation brought on by a diagnosis of infertility. ${ }^{75}$

In conclusion, this article calls for transparent review of a criminal penalty which has hitherto never been subject to public debate. This article does not predict that the outcome of a review of the criminalization of commercial surrogacy will result in a removal of criminal sanction. ${ }^{76}$ Rather its aim is to caution against the continued application of what may well be outdated criminal policy with respect to commercial surrogacy given a fundamentally changed social, economic, technological and global environment.

and the Deep Freeze: Is There International Consensus in the Debate over Assisted Reproductive Technologies' 19 Houston Journal of International Law 147 at 150 citing the Warnock report at [1.8].

${ }^{72}$ John M Breen 'Modesty and Moralism: Justice, Prudence, And Abortion - A Reply to Skeel \& Stuntz' (2008) 31 Harvard Journal of Law \& Public Policy 221, 252.

${ }^{73}$ Men report feeling deeply demoralized and women have been shown to suffer from severe depression comparable to people who have terminal diseases see Alice D Demar et al. 'The Prevalence and Predictability of Depression in Infertile Women' 58 Fertility and Sterility, 1158, 1161-62 (1992).

${ }^{74}$ Jean Macchiaroli Eggen, 'The "Orwellian Nightmare" reconsidered: A proposed regulatory framework for the advanced reproductive technologies' (1991) 25(3) Georgia Law Review 627, 669.

${ }^{75}$ Judith F Daar, 'Accessing Reproductive Technologies: Invisible barriers, Indelible harms' (2008) 23 Berkeley Journal of Gender, Law \& Justice 18 at 30. Darr notes that the harm argument used in relation to children born of surrogacy is also transforming.

${ }^{76}$ There is ongoing support from some quarters for the criminalisation of commercial surrogacy, see for example, writing in 2008 Renate Klein explains and supports the twenty-five years of feminist resistance to reproductive engineering arguing that women and their babies are reduced '...to a series of body parts and tissues that can be traded, screened and eliminated at will.' Renate Klein 'From test-tube women to bodies without women' (2008) 31 Women's Studies International Forum 157-175 (this work has been undertaken by the organization FINNRAGE (Feminist International Network of Resistance to Reproductive and Genetic Engineering)). 